\title{
DESAIN DAN ANALISIS PEKERJAAN DALAM MANAJEMEN PERSONALIA
}

\author{
Mastura Minabari \\ Dosen FTIK IAIN Palu
}

Each work design also influences the employee's attitude towards the task at hand. In addition, job design determines work relations between employees, between employees and superiors, types of work, and socio-economic relations. Through design work is carried out changing the content, functions and relations of work that are able to complete in accordance with the target and boss satisfaction. Job design and analysis includes; authority of the office holder, routine implementation of duties, identity of the holder, and involvement of the incumbent. Job functions include; work methods used, work coordination, responsibility, information flow, and work authority. While employment relations include joint work activities between officials and all employees in one agency.

Keywords: official management, design work, design

Setiap desain pekerjaan turut mempengaruhi sikap pegawai terhadap tugas yang diembannya. Selain itu, desain pekerjaan menentukan hubungan kerja antarpegawai, antara pegawai dengan atasan, jenis pekerjaan, dan hubungan sosial-ekonomi. Melalui desain pekerjaan dilakukan pengubahan muatan, fungsi dan hubungan pekerjaan yang mampu menyelesaikan sesuai dengan target dan kepuasan atasan. Desain dan analisis pekerjaan meliputi; otoritas pemegang jabatan, rutinitas pelaksanaan tugas, identitas pemegang jabatan, dan keterlibatan pemegang jabatan. Fungsi pekerjaan meliputi; metode kerja yang digunakan, koordinasi pekerjaan, tanggung jawab, arus informasi, dan otoritas pekerjaan. Sedangkan hubungan pekerjaan mencakup aktivitas kerja bersama antarpejabat dan semua pegawai dalam satu instansi.

Kata kunci: desain, analisis pekerjaan, manajemen personalia. 


\section{Pendahuluan}

Desain pekerjaan adalah alat untuk mendorong dan memberikan tantangan kepada para staf pegawai atau karyawan. Agar desain pekerjaan dapat disusun dengan baik, diperlukan sistem kerja secara prosedural sehingga memudahkan pencapaian pelaksanaan tugas secara efektif dan efisien. Melalui desain pekerjaan diharapkan terjadi peningkatan produktivitas, mengurangi timbulnya rasa bosan, dan menghasilkan kepuasan kerja. Apabila desain pekerjaan tidak dianalisis sesuai dengan tugas pokok dan tanggung jawab sesuai dengan desain kinerja pegawai atau karyawan, maka menyebabkan hambatan dan kendala pada bidang kerja masingmasing, bahkan menimbulkan kegaduhan dan kegelisahan yang berakhir dengan lahirnya gejala "stres " di kalangan para pegawai atau karyawan.

Berdasarkan analisis tersebut di atas, maka diperlukan pentingnya desain dan analisis pekerjaan dalam manajemen personalia dalam satu instansi atau perusahaan. Menurut beberapa ahli manajemen berpendapat bahwa desain dan analisis pekerjaan merupakan salah satu faktor utama yang akan memajukan produktivitas dan kinerja instansi atau perusahaan.

Desain pekerjaan pada hakikatnya adalah perincian tugas atau suatu cara pelaksanaan subjek yang mengerjakan tugas, cara pelaksanaan tugas, tempat pelaksanaan tugas, dan hasil yang diharapkan ${ }^{1}$. Pendapat lain dikemukakan pula oleh Sulipan antara lain, bahwa; desain pekerjaan adalah fungsi penetapan organisasional yang bertujuan mengatur penugasan kerja agar kebutuhan organisasi terpenuhi dengan baik ${ }^{2}$. Sedangkan Dessler mengatakan, bahwa; desain pekerjaan merupakan pernyataan tertulis tentang hal-hal yang harus dilaksanakan pegawai, cara pelaksanaan, dan penjelasan mengenai kondisi kerjanya. Desain pekerjaan meliputi; identifikasi pekerjaan, hubungan tugas dan tanggung jawab,

${ }^{1}$ Eddy Herjanto .Manajemen Operasi. (Ed.3 Jakarta: Gramedia Widiasarana Indonesia, 2007), 89.

${ }^{2}$ Sulipan, Prosedur Penelitian Suatu Pendekatan Praktik (Ed. Revisi V, Jakarta: Rineka Cipta,2000), 75. 
standar wewenang pekerjaan, persyaratan kerja, dan struktur jabatan dalam organisasi yang menguraikan kedudukan jabatan terendah hingga tertinggi ${ }^{3}$. Demikian pula Handoko menyatakan bahwa, desain pekerjaan adalah fungsi penetapan tugas secara prosedural yang dibebankan kepada pegawai secara individu dan kelompok yang diorganisasikan secara struktural dengan tujuan mengatur penugasan tertentu bagi pegawai untuk memenuhi kebutuhan organisasi ${ }^{4}$. Hal yang serupa dikemukakan pula oleh Dwiningsih, bahwa; dalam desain pekerjaan terdapat metode dan pendekatan yang menentukan tugas suatu pekerjaan bagi pegawai dan hubungan antarpegawai dalam suatu instansi atau perusahaan. Hal ini bertujuan agar pencapaian kinerja dapat terwujud dengan baik, efektif serta efisien $^{5}$.

Robbins \& Coulter (2002) mendefinisikan desain atau perencanaan sebagai sebuah proses yang dimulai dari penetapan tujuan institusi (lembaga atau perusahaan), menentukan strategi untuk pencapaian tujuan institusi tersebut secara menyeluruh serta merumuskan sistem perencanaan yang menyeluruh untuk mengintegrasikan dan mengordinasikan seluruh pekerjaan institusi sehingga mencapai tujuan;" Planning is a process that involves defining the organization's goals establishing an overal strategy for achiefing those goals, and developing a comprehensive set of plan to integrate and coordinate organizational work. ${ }^{6}$

Perencanaan akan menghasilakn upaya untuk meraih sesuatu dengan cara yang lebih terkoordinasi. Institusi atau perusahaan yang tidak menjalankan perencanaan dengan baik akan mengalami konflik kepentingan, pemborosan sumber daya, dan ketidakberhasilan dalam pencapaian tujuan, karena bagianbagian dalam struktur kepegawaian akan bekerja secara sendirisendiri tanpa adanya koordinasi yang jelas dan terarah. Robert

${ }^{3}$ Dessler, Gary, Human Resource Management International Edition 8 th Ed,(New Jersey Prentice Hall, Inc, Upper Saddle River,2000), 172

${ }^{4}$ Hani.T.Handoko, Manajemen Personalia dan SDM (Yogyakarta: BPFE, 1987), 88

5 Dwiningsih,N. 2009.Strategi Operasi dalam Lingkungan Global(Jakarta: STEKPI,2009),37 
Kreitner mengemukkan bahwa sebuah institusi atau perusahaan harus menjalankan fungsi dari sebuah perencanaan, karena fungsi perencanaan merupakan standar pengawasan kualitas yang memiliki manfaat untuk; (1) perencanaan sebagai pengarah, (2) perencanaan sebagai upaya untuk meminimalisasi ketidakpastian, (3) perencanaan sebagai upaya meminimalisasi pemborosan sumber daya, dan (4) perencanaan sebagai penetapan standar dalam pengawasan kualitas ${ }^{6}$.

Berdasarkan beberapa pendapat di atas dapatlah ditetapkan bahwa desain pekerjaan bertujuan merakit sejumlah perencanaan sebagai tugas pokok yang menjadi pekerjaan agar lebih terarah dan jelas. Secara umum pula dapat dikemukakan bahwa desain pekerjaan menghendaki agar:

1. Efisiensi operasional, produktivitas dan kualitas pelayanan menjadi optimal.

2. Fleksibilitas dan kemampuan melaksanakan proses kerja secara horizontal dan hierarki (struktural).

3. Minat, tantangan dan prestasi menjadi optimal.

4. Tanggung jawab team ditetapkan sesuai standar tupoksi sehingga dapat meningkatkan kerjasama yang efektif dan efisien.

5. Integrasi kebutuhan individu, dan para pegawai (karyawan) dengan kebutuhan organisasi.

Kelima tujuan secara umum tersebut di atas merupakan prioritas utama, walaupun pada dasarnya jenis dan pembagian tugas pekerjaan tetap disesuaikan dengan keahlian.

\section{Pedoman Desain dan Analisis Pekerjaan}

Perencanaan pesonalia merupakan langkah-langkah perumusan program yang akan dilaksanakan berkaitan dengan kebutuhan pegawai, tugas dan kewajiban pegawai, penambahan ataupun pengurangan pegawai, dan penugasan pekerjaan yang baru kepada pegawai. Beberapa ahli manajemen memberikan definisi mengenai desain personalia antara lain;

6 Robert Kreitner, Management Principles and Practices, (Houghton: Mifflin Company,1995), 100 
"Perencanaan personalia adalah perencanaan tenaga kerja yang merupakan proses penentuan kebutuhan tenaga kerja yang mempertemukan kebutuhan agar pelaksanaannya berinteraksi dengan rencana institusi ${ }^{7}$.

George Milkovich dan Paul C.Nystrom yang dikutip oleh Dale Yoder, mendefinisikan, bahwa perencanaan tenaga kerja adalah proses peramalan, pengembangan, pengimplementasian, dan pengontrolan yang menjamin perusahaan mempunyai kesesuaian jumlah pegawai, penempatan pegawai secara benar, waktu yang tepat, dan bermanfaat $^{8}$. Hal yang serupa dikemukakanpula oleh Mangkunegara, bahwa perencanaan tenaga kerja adalah proses penentuan kebutuhan tenaga kerja berdasarkan peramalan, pengembangan, pengimplementasian, dan pengendalian kebutuhan yang berintegrasi dengan perencanaan institusi agar tercipta jumlah pegawai yng tepat dan bermanfaat secara ekonomis ${ }^{9}$.

Berdasarkan beberapa pendapat di atas dapat disimpulkan bahwa perencanaan personalia adalah perumusan yang berkaitan dengan upaya estimasi kebutuhan tenaga kerja untuk masa yang akan datang terhadap institusi atau lembaga. Melalui perencanaan personalia yang matang, efektivitas kerja akan lebih baik dan menguntungkan. Hal ini terwujud apabila sumber manusianya lebih terampil dan profesional dan ditunjang oleh standart operating procedure (SOP) sebagai pedoman kerja yang lebih mudah dipraktikkan, suasana kerja kondusif, perangkat kerja sesuai dengan tugas masing-masing, SDM telah tersedia dengan baik, adanya jaminan keselamatan kerja, berdasarkan kebutuhan dan beban kerja.

Desain pekerjaan mencakup beberapa hal antara lain; (1) identitas pekerjaan, (2) hubungan tugas dan tanggung jawab, (3) standar wewenang dan pekerjaan, (4) syarat kerja yang

${ }^{7}$ Dale Yoder.1981.Personnel Management and Industrial (Relation New Delhi: Prentice Hall of India.1981),48 2014), 49.

${ }^{8}$ Kadar Nurjaman, Manajemen Personalia, (Badung: Pustaka Setia,

9 Prabu Mangkunegara, Perencanaan dan Pengembangan SDM, (Bandung: Revika Aditama, 2002), 67. 
teruraikan dengan jelas, (5) ringkasan pekerjaan, dan (6) penjelasan tentang jabatan ${ }^{10}$.

Pembagian dan perluasan tugas (job enlargement) meliputi pemberian tugas yang lebih besar secara horizontal tetapi pekerjaan tambahan itu berada pada tingkat kecakapan dan tanggung jawab yang setara dengan pekerjaan semula. Perluasan pekerjaan ditujukan agar tanggung jawab dan wewenang pegawai (karyawan) lebih besar. Pengayaan tugas (job enrichment) mencakup penambahan tugas dengan tanggung jawab yang lebih tinggi seperti perencanaan dan pengendalian. Sedangkan pertukaran, mutasi(rolling) yaitu; melakukan tugas antarpegawai secara periodik untuk menghindari rutinitas dan pekerjaan pegawai yang monoton.Analisis pekerjaan adalah proses pengumpulan informasi mengenai pekerjaan yang dilakukan oleh pegawai dengan mengamati dan mengadakan wawancara terhadap pegawai dengaan bukti-bukti yang benar dari pemegang jabatan dan pengendali jabatan (pemangku jabatan) sesuai jenjang struktural maupun fungsional.

Analisis pekerjaan ini menghasilkan daftar uraian pekerjaan dan pernyataan tertulis mengenai kewajiban pegawai mencakup standar kualifikasi pendidikan dan pekerjaan minimal yang diperlukan bagi seorang pekerja untuk melaksanakan tugas dan kewajiban dari kedudukannya agar memuaskan lembaga. Analisis pekerjaan dilakukan untuk menilai keterampilan pegawai, produktivitas dan analisis jabatan tertentu. Selain untuk menghilangkan kejenuhan, analisis jabatan juga memperkaya pendekatan dan teknis pelaksanaan pekerjaan agar produktivitas kerja meningkat secara kuantitatif dan kualitatif. Setelah mendapatkan analisis pekerjaan, instansi (lembaga atau perusahaan) dapat melakukan tiga keputusan untuk memperbaiki kondisi pekerjaan yang terlalu spesialisasi antara lain; perancangan kembali dengan rotasi jabatan, pemerkayaan pekerjaan secara horizontal (job

10 F.C.Gomes, Manajemen Sumber Daya Manusia, (Yogyakarta: Andi, 2002), 51. 
enlargement) dan pemerkayaan pekerjaan secara vertikal (job enrichment).

Hasil analisis pekerjaan merupakan informasi penting bagi instansi dan fihak yang bekerja sama dengan lembaga lain sehingga informasi analisis pekerjaan dapat dipergunakan untuk hal-hal berikut:

1. Menetapkan dasar pemberian kompensasi

2. Mengevaluasi faktor-faktor lingkungan yang mempengaruhi pekerjaan.

3. Menghilangkan persyaratan-persyaratan kerja yang menyebabkan diskriminasi pekerjaan individual.

4. Merencanakan kebutuhan pengadaan sumber daya manusia untuk waktu yang akan datang.

5. Memadukan lamaran-lamaran dengan kualifikasi yang ada

6. Meramalkan dan menentukan kebutuhan latihan bagi karyawan baru dan lama, serta mengembangkan karyawan yang potensial.

7. Menetapkan standar prestasi kerja yang realistis.

8. Menetapkan karyawan sesuai dengan kemampuan dan keterampilannya.

9. Membantu revisi struktur organisasi dan memperbaiki aliran kerja.

10. Orientasi karyawan ${ }^{11}$.

Dalam membuat analisis pekerjaan tedapat beberapa metode yang dapat diguakan untuk memperoleh data dan fakta yang akurat dan dapat diverifikasi validitasnya. Metode tersebut adalah sebagai berikut:

1. Metode wawancara dengan cara mengadakan percakapan langsung dengan para pegawai yang dilaksanakan di tempat mereka bekerja sesuai dengan kesiapan mereka. Metode wawancara dimulai dengan mengajukan pertanyaanpertanyaan yang berkaitan dengan identitas pegawai, pendidikan, usia, spesialisasi, tugas, jabatan dan hal-hal lain yang berkaitan dengan pekerjaannya, atau diperdalam dengan menanyakan mengenai manajemen instansi,

11 WR. Mondy \& Robert M. Noe.Human Recourses and Management, (Allyn and Bacon, 1993),.59 
kepemimpinan, pertanggungjawaban, gaji, bonus, dan sebagainya.

2. Metode observasi, dilakukan dengan mengamati pegawai pada saat melaksanakan tugasnya secara langsung.

3. Metode angket, berisi daftar pertanyaan yang harus diisi oleh responden atau permintaan jawaban dari responden dalam bentuk tertulis. Pegawai sebagai responden diharapkan memberikan data mengenai jabatannya. Analisis bertujuan meminta pegawai menjawab pertanyaan untuk menggambarkan tugas berkaitan dengan jabatan dan tanggung jawabnya.Hasil pengumpulan data melalui angket harus diklasifikasikan dan diuji berdasarkan pendekatan kuantitatif.

4. Metode catatan karyawan menganalisis pekerjaan dikumpulkan dengan meminta para karyawan mendeskripsikan aktivitas kerjanya sehari-hari dalam sebuah buku harian atau log.

5. Metode kombinasi melakukan penelitian dengan menggabungkan semua

6. Metode pengumpulan data, yaitu; observasi, angket, wawancara, dan catatan

karyawan untuk dijadikan metode secara bersamaan sehingga data-data yang diperoleh lebih akurat dan mendalam $^{12}$.

Proses Analisis Pekerjaan dan Tantangannya

Fungsi-fungsi manajemen yang dijalankan menurut tahapan tertentu sangat berbeda apabila didasarkan pada fungsi operasionalnya. Hal ini terlihat apabila fungsi perencanaan untuk SDM akan sangat berbeda dengan fungsi perencanaan untuk SDA/fisik misalnya bidang keuangan. Demikian pula untuk fungsi pengorganisasiannya, maupun pengawasannya. Fungsi perencanaan, pengorganisasian, pengarahan dan pengawasan bagi organisasi politik akan berbeda dengan organisasi bisnis atau organisasi sosial. Demikian pula sebuah

${ }^{12}$ Sunarto. Manajemen Karyawan, (Yogyakarta: Amus, 2005), 75. 
institusi pendidikan atau pemerintahan. Namun secara umum memiliki kesamaan model manajemen.

Abdul Hakim mengemukakan bahwa sistem manajemen kepegawaian pada sebuah institusi lebih mengarah pada:

1. Undang-Undang Nomor 22 tahun 1999 tentng Pemerintahan Daerah.

2. Undang-Undang Nomor 43 Tahun 1999 tentang Perubahan Atas Undang-Undang Nomor 8 Tahun 1974 tentang PokokPokok Kepegawaian.

3. Keputusan Menteri Dalam Negeri Nomor 45 Tahun 1992 tentang Pokok-Pokok Kebijaksanaan Sistem Informasi Manajemen Departemen Dalam Negeri dan Pemerintahan Daerah (SIMDAGRI/SIMDA).

4. Keputusan Menteri Dalam Negeri Nomor 140 Tahun1997 tentang Rencana Induk Pengembangan Sistem Informasi Manajemen Departemen Dalam Negeri dan Pemerintah Daerah.

5. Keputusan Menteri Dalam Negeri Nomor 17 Tahun 2000 tentang Sistem Informasi Manajemen Kepegawaian Departemen Dalam Negeri dan Pemerintah ${ }^{13}$.

Analisis pekerjaan merupakan proses pengumpulan evaluasi, pengorganisasian informasi mengenai perancangan pekerjaan, pemahaman pekerjaan, persyaratan-persyaratan.

Selanjutnya analisis pekerjaan memiliki tahapantahapan; 1) Persiapan Awal, mencakup beberapa hal yaitu Identifikasi pekerjaan dan penyusunan daftar pertanyaan, pemutusan informasi; 2) Pengumpulan Data, dilakukan melalui observasi, wawancara, angket, catatan karyawan, dan kombinasi; 3) Penyempurnaan Data, menyeleksi dan mengklasifikasikan data yang diperoleh dengan tujuan mendapatkan informasi tentang deskripsi pekerjaan, spesifikasi pekerjaan dan standar-standar pekerjaan ${ }^{14}$.

13 Husein Umar, Metode Riset Ilmu Administrasi: Ilmu Administrasi Negara, Pembangunan dan Niaga, (Jakarta: Gramedia Pustaka Utama, 2004), 123.

${ }^{14}$ Sudarmayanti, Sumber Daya Manusia dan Produktivitas Kerja, (Bandung: Mandar Maju, 2002), 33 
Berdasarkan penjelasan-penjelasan tersebut di atas dapat dipahami bahwa desain pekerjaan dibuat oleh organisasi untuk mengatur tugas-tugas yang tepat sasaran dan memberikan tugas kepada pegawai atau karyawan dengan kemampuan dan keterampilan tertentu demi mencapai sasaran dan tujuan yang tepat. Desain pekerjaan berfungsi untuk menetapkan kegiatan kerja individu atau kelompo pegawai secara organisasional dengan tujan mengatur penugsan kerja untuk memenuhi kebutuhan organisasi.

Rina Novianty Ariaty mengatakan bahwa dalam menganalisis pekerjaan dihadapkan pada dua tantangan yakni eksternal dan internal. Tantangan eksternal adalah tantangan yang berasal dari luar institusi atau perusahaan yang antara lain; (1) tantangan ekonomi, (2) kondisi geografis, (3)kondisi sosial budaya, (4) tantangan politik dan pemerintah, (5) tantangan demografis, (6) pasar kerja, (7) kegiatan-kegiatan pesaing, (8) langkah-langkah yang diambil manajemen SDM, (9) monitor lingkungan, (10) evaluasi dampak perubahan, (11) tindakan-tindakan proaktif, (12) menganalisis umpan balik.

Sedangkan tantangan internal sebuah institusi atau lembaga terdiri dari; (1) karakter organisasi, (2) serikat pegawai (karyawan), (3) sistem informasi, (4) perbedaanperbedaan individual karyawan, (5) sistem nilai manager dan pegawai, (6) pola kepemimpinan manager, (7) keterampilan karyawan $^{15}$.

\section{Penutup}

Fungsi perencanaan (planning) merupakan arah penentu dari sebuah organisasi/institusi atau perusahaan yang akan meminimalisasi ketidakpastian penetapan standar pencapaian terhadap tujuan atau visi-misi sebuah institusi. Desain perencanaan dan analisis pekerjaan harus memenuhi kriteria

15 R.Rina Novianty Ariawaty, "Pengaruh Pengembangan Sumber Daya Manusia, Kompetensi Individu dan Kepuasan Kerja Terhadap Kinerja Manajer Tingkat Dasar. Studi pada PT Kereta Api di Pulau Jawa", (Bandung: Disertasi Universitas Padjadjaran tidak diterbitkan, 2007), 101. 
realistis,faktual,fleksibel, logis dan rasional serta memiliki komitmen yang komprehensif.

Sebuah Lembaga (institusi) atau perusahaan seringkali berhadapan dengan berbagai alternatif keputusan untuk kinerja para pegawai, oleh karena itu, diperlukan kebijaksanaan tatakelola (pimpinan hingga bawahan secara struktural) mempertimbangkan berbagai faktor dan alternatif yang bersifat aturan fomal (resmi) dan situasional sehingga tujuan institusi dapat berjalan dan berkembang dengan baik.

\section{Daftar Pustaka}

Ariawaty, R.Rina Novianty, 2007. Pengaruh Pengembangan Sumber Daya Manusia,Kompetensi Individu dan Kepuasan Kerja Terhadap Kinerja Manajer Tingkat Dasar. Studi pada PT Kereta Api di Pulau Jawa. Bandung: Disertasi Universitas Padjadjaran.

Dwiningsih N. 2009. Strategi Operasi dalam Lingkungan Global.Jakarta: STEKPI,

Dessler, Gary. 2000. Human Resource Management International Edition 8 th Ed. New Jersey Prentice Hall, Inc, Upper Saddle River,

Gomes, FC, 2002. Manajemen Sumber Daya Manusia. Yogyakarta: Andi.

Herjanto, Eddy, 2007. Manajemen Operasi, (Ed. 3 Jakarta: Gramedia Widiasarana Indonesia.

Handoko, T. Hani. 1987. Manajemen Personalia dan SDM. Ed.2.Yogyakarta: BPFE.

Mangkunegara, Prabu, 2002. Perencanaan dan Pengembangan SDM. Bandung: Revika Aditama.

Mondy,WR \& Robert M. Noe. 1993 Human Recourses and Management. Allyn and Bacon. 
Nurzaman, Kadar, 2014. Manajemen Personalia. Badung: Pustaka Setia.

Robert Kreitner. 1995. Management Principles and Practices. Houghton Mifflin Company.

Sunarto. 2005. Manajemen Karyawan, Yogyakarta: Amus.

Sulipan, 2000. Prosedur Penelitian Suatu Pendekatan Praktik.Ed.Revisi V, Jakarta: Rineka Cipta.

Sule, Erni Tisnawaty \& Kurniawan Saefullah, 2017. Pengantar Manajemen. Cetakan ke-10.Jakarta: Prenada Media Group.

Sudarmayanti, 2002. Sumber Daya Manusia dan Produktivitas Kerja.Bandung: Mandar Maju.

Yoder, Dale, 1981. Personnel Management and Industrial. Relation New Delhi: Prentice Hall of India.

Umar, Husein, 2004. Metode Riset Ilmu Administrasi: Ilmu Administrasi Negara, Pembangunan dan Niaga. Jakarta: Gramedia Pustaka Utama. 